\title{
Reducing DMU fuel consumption by means of hybrid energy storage
}

\author{
Holger Dittus • Dirk Hülsebusch • Jörg Ungethüm
}

Received: 3 September 2010 / Accepted: 16 June 2011 /Published online: 30 June 2011

(C) The Author(s) 2011. This article is published with open access at Springerlink.com

\begin{abstract}
Purpose This paper discusses a hybrid energy storage concept and its control strategy for hydro-mechanical DMUs. The hybrid energy storage consists of double layer capacitors and batteries. The new concept aims on reducing fuel consumption and avoiding unhealthy emissions during idling in station area.

Methods Development of a hybrid propulsion concept and control strategy requires adequate methods for modeling system behavior. The simulation environment Dymola is used to develop and evaluate the control strategy and for dimensioning the system components.

Results Simulations indicated fuel savings of up to $13 \%$ depending on track characteristics. Measurements of a scaled storage system in a HiL-environment showed good accordance of the simulated and measured behavior of battery and double layer capacitor.

Conclusions The newly developed storage system and its control strategy enable reduction of fuel consumption and unhealthy emissions in station areas.
\end{abstract}

Keywords Diesel multiple unit · Control strategy · Hybrid energy storage $\cdot$ Hardware in the loop $\cdot$ Fuel consumption

This work was originally presented on 10th Stuttgart International Symposium "Automotive and Engine Technology"

H. Dittus $(\bowtie) \cdot$ D. Hülsebusch $\cdot$ J. Ungethüm Institut für Fahrzeugkonzepte,

Deutsches Zentrum für Luft- und Raumfahrt e.V.,

Stuttgart, Germany

e-mail: holger.dittus@dlr.de

\section{Introduction}

During the last ten years the general requirements for rail vehicles have changed mainly. The development is driven by

- increasing energy costs

- growing importance of life cycle costs compared to investment costs

- challenging emission regulations for diesel powered vehicles

- competition with other modes of transport.

As part of the Next Generation Train (NGT) project presented at InnoTrans 2008 scientists of German Aerospace Center (DLR) are developing intelligent concepts to meet future demands of vehicle requirements. In Germany diesel multiple units (DMU) are widely used in regional traffic on non-electrified lines. In 2003 Deutsche Bahn operated about 1300 DMUs [1] and in 2004 more than $75 \%$ of diesel traction train kilometres of Deutsche Bahn were accomplished by DMUs. This is a share of $18.1 \%$ of Deutsche Bahn's overall train kilometres in passenger transport [2]. DMUs are essential to provide passenger service in regional traffic on lines with low utilization. They are either single coaches or fixed coupled coaches consisting of 2 or max. 3 power cars. Normally each power car is driven by one medium power diesel engine $(250 \mathrm{~kW}-560 \mathrm{~kW})$ which is often a derivate of truck or industrial engines. Basically three variants of propulsion systems are used in DMUs: diesel-electric, diesel-hydraulic and diesel-hydro-mechanical. In terms of efficiency the hydro-mechanical propulsion system is superior to the other ones, reaching a maximum efficiency of $95 \%$ compared to $85 \%$ for electric and hydraulic power trains $[3,4]$. 
The diesel engine also powers auxiliary systems such as air compressors, engine cooling, air conditioning and electric onboard system. In literatures [4-7] the share of energy used for the auxiliary systems ranges between $5 \%$ and more than $20 \%$ of total fuel consumption depending on source of information and use case. Typical engine load profiles of DMUs point out that the engine is operated at low load over a significant amount of time, for example during station stops when the engine is only powering auxiliary loads. According to [8] a typical DMU in Germany is stopped for about $30 \%$ of time. Measurements performed by the Danish public transport provider DSB show that the maximum engine power is requested only for about $21 \%$ of time while for more than $41 \%$ of time the engine is idling with low or no load [9]. As a result of low load the overall efficiency of a diesel engine is far away from its optimum resulting in increased fuel consumption as well as noise and pollutant emissions during station stops.

Typical operational cycles of DMUs consist of 4 phases: Acceleration, cruising, coasting and braking (Fig. 1). During acceleration high traction power is needed while when cruising with constant speed traction power is only needed to overcome the resistance forces. In the coasting phase no traction power is applied. The kinetic energy keeps the vehicle rolling while speed decreases due to the resistance forces. Optionally auxiliary units are powered by recuperated energy during this phase. In the braking phase the vehicle decelerates using mechanic brakes, hydrodynamic brakes or electric drives with brake resistors [10]. Typically, journey time between two stations is fixed in the time table. If the acceleration is increased by providing additional power in the acceleration phase (boost-effect) then the better performance helps extending the coasting phase where no traction power is applied, eventually leading to improved fuel economy [11].

In conventional DMUs recuperation of braking energy is not possible and the kinetic energy is dissipated by the brake systems. In contrast electric vehicles typically recuperate 12 to $42 \%$ of line energy (depending on type

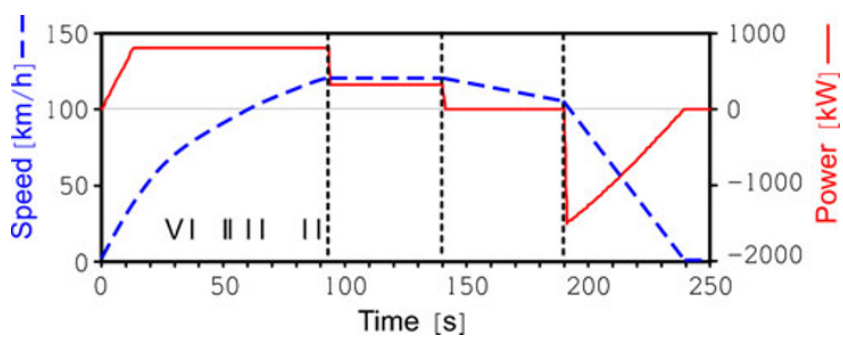

Fig. 1 Typical operational cycle of DMU with acceleration (I), cruising (II), coasting (III) and braking phase (IV). Maximum speed $120 \mathrm{~km} / \mathrm{h}$, travelled distance $5 \mathrm{~km}$, max. acceleration $1.0 \mathrm{~m} / \mathrm{s}^{2}$, brake deceleration $0.6 \mathrm{~m} / \mathrm{s}^{2}$ of service, driving style, network characteristics, vehicle type...) $[5,12,13]$. One option to recuperate braking energy in DMUs is the use of onboard energy storages [1417]. Measurements done on diesel electric multiple units with two $200 \mathrm{~kW}$ energy storages showed a fuel consumption reduction of more than $8 \%$ during driving [18]. For a generic DMU (mass $102 \mathrm{t}$, vMax $120 \mathrm{~km} / \mathrm{h}$, deceleration $0.6 \mathrm{~m} / \mathrm{s}^{2}$, regenerative braking for $\mathrm{v}>10 \mathrm{~km} / \mathrm{h}$ ) roughly 14 $\mathrm{kWh}$ of braking energy are available at the wheel. The amount of recoverable braking energy is limited by maximum power of the storage system. Fig. 2 displays the correlation of vehicle speed, maximum storage power and storable braking energy at wheel for the whole vehicle. With a $200 \mathrm{~kW}(300 \mathrm{~kW})$ storage system roughly $2.8 \mathrm{kWh}$ $(4.1 \mathrm{kWh})$ could be regenerated in the braking phase.

Based on the topics described above the following requirements for a concept of a hybrid hydro-mechanical DMU are defined:

1. Improve fuel economy by recuperation of braking energy.

2. Increase overall engine efficiency by avoiding low load engine operation.

3. Avoid noise and emissions within stations by switching off diesel engines and powering auxiliary systems with stored energy.

4. Provide additional traction power while accelerating (boost-effect).

This paper discusses a new hybrid propulsion concept for hydro-mechanical DMUs. For the hybrid propulsion system an energy storage system consisting of double layer capacitors and batteries is developed. It is modelled as part of the DMU propulsion system to compare performance and fuel consumption of the hybrid against a conventional DMU. In the second part of the paper the integration of the simulation model in hardware in the loop environment is described. The DMU model is used to simulate train environment and drive train while a scaled energy storage including converter and auxiliary load is built up in hardware on a test bench. Through this approach both the thermal and electrical behaviour of this energy storage system in the given application are evaluated.

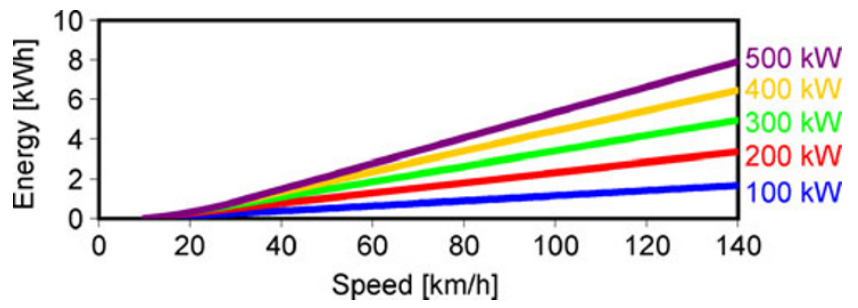

Fig. 2 Storable braking energy for different velocities and energy storage charge powers $\left(102 \mathrm{t}\right.$, deceleration rate $0.6 \mathrm{~m} / \mathrm{s}^{2}$, regeneration of braking energy possible for $\mathrm{v}>10 \mathrm{~km} / \mathrm{h}$ ) 


\section{Development of a hybrid propulsion concept}

The generic DMU considered in the following is equipped with two power packs each consisting of diesel engine, transmission, generator and auxiliaries (Fig. 3). The sixspeed transmission includes a hydrodynamic torque converter for start-up when standing. A converter lockup clutch enables controlled bridging of the torque converter; if bridged the first gear operates like a mechanic gear. Gears two to five are mechanic gears. In DMUs auxiliaries are either powered mechanically, electrically or hydrostatically. Because generator and electrical onboard system are already on the vehicle electrically powered auxiliaries are assumed for the conventional and hybrid DMU. The hybrid DMU concept is based on the layout of the conventional DMU. Basically the layout is a parallel hybrid system using an electric drive mounted between diesel engine and transmission (Fig. 4). The electric drive replaces the generator of the conventional DMU. A clutch mounted between diesel engine and electric drive allows disconnecting and switching off the diesel engine during coasting and braking.

\subsection{Energy storage system}

A storage system for the described application should fulfil the following requirements (all numbers account for one power pack):

- discharge power for auxiliaries in stand still $35 \mathrm{~kW}$, during acceleration $55 \mathrm{~kW}$

- traction support power $100 \mathrm{~kW}$, charge power in braking phase $150 \mathrm{~kW}$

- required energy during stand still $2.9 \mathrm{kWh}(35 \mathrm{~kW}$ for 5 min)

- high operational availability, robustness, redundancy, lifetime

- additional mass of the energy storage components is limited to $1 \mathrm{t}$ per power pack

For the given application double layer capacitors and batteries are taken into account. Flywheel storage systems are not considered because they are still under development, mechanically complex and some safety issues are still open [19]. The main advantages of double layer capacitors are high power density and a great number of load cycles. The disadvantages are limited energy density and therefore high costs for high energy applications. Batteries on the other hand can store more energy but are more expensive

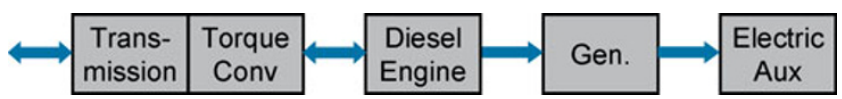

Fig. 3 Traction drive schematic of conventional DMU with electric auxiliaries

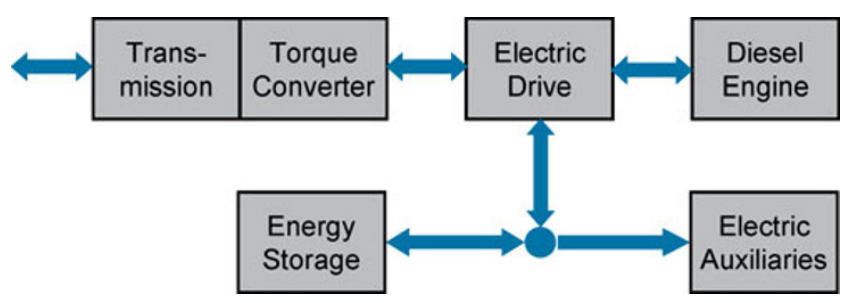

Fig. 4 Traction drive schematic of hybrid DMU with energy storage and electric drive

concerning power. The main disadvantage of batteries is lifetime in terms of duty cycles. While double layer capacitors provide up to 1 million duty cycles batteries only last for up to 5000 duty cycles when the full capacity is used [20,21]. Therefore only a limited range of 10 to $20 \%$ of the available energy is used during charge and discharge cycles.

The energy storage in the hybrid DMU has to fulfil two main requirements:

- When the DMU is stopped, discharge power of the storage is low but the amount of energy required sums up over time. This discharge profile would perfectly fit to battery storage.

- During braking energy is available in a short period of time requiring high power capability. Double layer capacitors would fit very well to this load profile.

The main requirements for the energy storage are a usable capacity of $2.9 \mathrm{kWh}$ and a charge power of $150 \mathrm{~kW}$. Based on these requirements double layer capacitor storage, battery storage and hybrid energy storage (HES) consisting of double layer capacitors and batteries are compared. The concept of hybrid energy storage is already discussed for use in light railway vehicles [22]. The idea is to combine the advantages of both storage technologies and to eliminate the disadvantages as far as possible. Each of the storage systems is sized according to the requirements mentioned above. For the double layer capacitor storage the usable energy determines the storage sizing while for the battery storage the charge power is the dominant criterion. Table 1 displays the resulting storage characteristics based on selected technical specifications of each storage technology $[23,24]$. The hybrid energy storage weighs $20 \%$ less than the other alternatives while its usable capacity and charge power exceed the requirements. Therefore the hybrid energy storage is chosen for the given application.

In the hybrid DMU with HES the battery is used to power the auxiliaries in stand still and during acceleration. The power demanded from the battery is limited by the maximum power of the auxiliaries keeping mass and costs of the battery system low. Because of the low charge power it is not possible to store the energy requested for long station stops during the braking phase. Therefore the battery 
Table 1 Comparison of storage designs for given requirements based on $[23,24]$

\begin{tabular}{llccc}
\hline & Unit & Double layer capacitor storage & Battery storage & Hybrid energy storage \\
\hline Power & $\mathrm{kW}$ & 445 & 180 & 240 \\
Usable Energy & $\mathrm{kWh}$ & 3.18 & $8.95(10 \% \mathrm{DoD})$ & 4.26 \\
Storage mass & $\mathrm{kg}$ & 1136 & 1152 & 839 \\
\hline
\end{tabular}

is also charged during cruising and coasting phase. Due to safety reasons a Lithium-Iron-Phosphate battery system is chosen. Compared to other Lithium battery systems this material combination provides very good thermal stability and high performance in terms of power and lifetime at relatively low costs [25]. The double layer capacitors are mainly used to recuperate braking energy with high power and to support traction.

\subsection{Hybrid energy storage topology}

Basically three topologies are possible for the hybrid storage. Each concept has its advantages and drawbacks which are discussed in the following.

The passive HES is the simplest topology (Fig. 5). It sets aside usage of the full capacity respectively the full voltage range of the double layer capacitor storage. It provides the possibility to damp short power peaks with the double layer capacitor storage and to provide power from the battery over longer periods of time. The voltage level of storages and auxiliary systems is almost constant. There is no need for adaptation of double layer capacitor and battery voltage because they are always the same. Therefore the requirements concerning the voltage range of the electric drive inverter are low. In addition no extra converter is necessary resulting in cost savings for power electronics. The parallel connection of both storages causes redundancy and safeguards the system against failure. The main drawback is that no active control of double layer capacitor and battery is possible resulting in low utilization of double layer capacitor capacity.

In the active HES with constant terminal voltage the double layer capacitor storage is connected to the battery via a bidirectional DC/DC converter (Fig. 6). Double layer

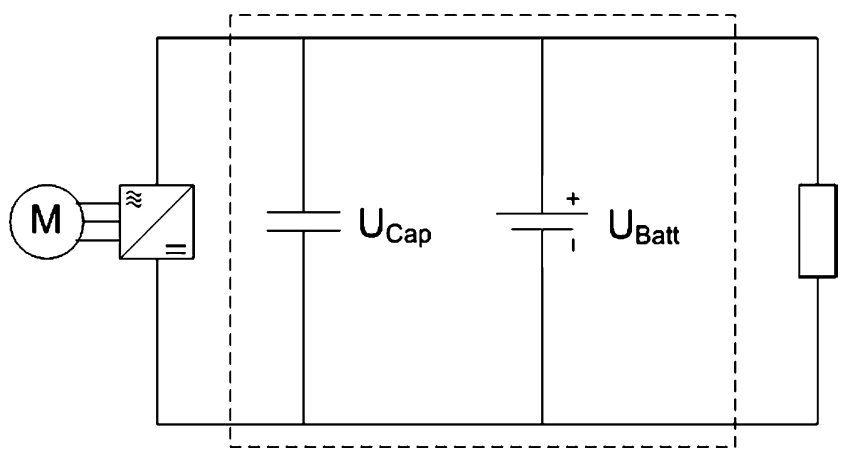

Fig. 5 Passive hybrid energy storage capacitor voltage is either always above or always below battery voltage to leave a 2-quadrant step down or step up DC/DC-converter sufficient. The decoupling of battery and double layer capacitor voltage allows utilizing a wide range of double layer capacitor capacity while the voltage level of electric drive and auxiliaries remains almost constant resulting in lower requirements for the associated power electronics. This topology also provides redundancy of battery and double layer capacitor; if one of the storage systems fails, then the auxiliaries are powered by the remaining storage system. Main disadvantages result from the necessity for a bidirectional DC/DC converter with high power capability eventually leading to high costs, high mass and increased converter losses. In addition the response time of the $\mathrm{DC} / \mathrm{DC}$-converter has to be low to avoid short peaks in battery power.

In the active HES with variable terminal voltage the double layer capacitor storage is connected directly to the inverter of the electric drive (Fig. 7). The double layer capacitor storage is intended to work in a voltage range above battery and auxiliary voltage. The stored energy may be used for traction support and/or to power auxiliaries. Battery storage and auxiliaries are connected in parallel using the same almost constant voltage level. They are connected to the double layer capacitor via a DC/DCconverter. The DC/DC-converter is unidirectional with relatively low power requirement lowering power electronics expenses. By a switchable line connecting double layer capacitor and auxiliaries high redundancy in case of battery or converter failure is achieved. The main disadvantage of this concept is the extended voltage range of the electric drive inverter. In this system traction support with battery energy is not possible, but due to the low power capability of the battery this is only a minor drawback.

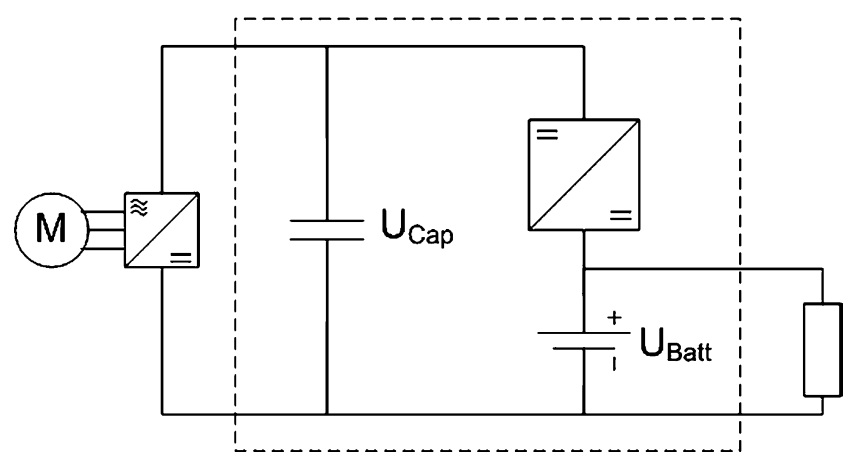

Fig. 6 Active hybrid energy storage with constant terminal voltage 


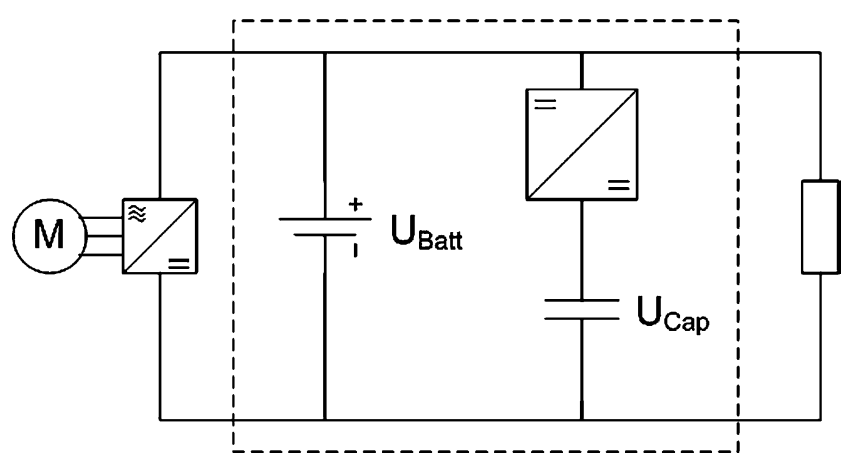

Fig. 7 Active hybrid energy storage with variable terminal voltage

For the hybrid DMU concept the third topology (active HES with variable terminal voltage) is chosen because it offers the most advantages in the given application.

\section{Modelling and simulation}

Performance and fuel consumption of the hybrid DMU are compared to a conventional DMU in simulations with identical general conditions. In both cases only half of the train (one power pack) is modelled; therefore all results shown account for one power pack. The DMUs are modelled in the simulation environment Dymola using the modelling language Modelica [26]. All models used are part of the modelling libraries "AlternativeVehicles" and "RailwayVehicles" which are developed by German Aerospace Center [27]. Fig. 8 shows the top layer of the hybrid DMU model including the main components such as internal combustion engine, gearbox, electric motor and energy storages. Table 2 summarizes characteristic parameters of conventional and hybrid DMU. Driving resistance coefficients are identical but the vehicle mass of the hybrid DMU exceeds the conventional DMU's mass by one ton per power pack.

\subsection{Auxiliary load profile and driving cycles}

The auxiliary systems are distinguished between air conditioning, air compressor and electric onboard systems. While engine cooling power is modelled as a constant share (4\%) of the actual engine power the auxiliaries are each modelled as a repeating time dependent load profile characterised by maximum power, power share and duty ratio. Fig. 9 displays the resulting time dependent load profile. During station stops the auxiliaries are powered either by the diesel engine or by the energy storage.

For the simulation runs synthetic driving cycles on a level track are used. Real life cycles have not been used to ensure easy understanding of the results and to avoid the optimization of the storage system for exactly one specific drive cycle. The drive cycles used represent typical operational profiles of regional DMUs. They are defined by station distance, maximum velocity, time reserve and deceleration rate in the braking phase. Departure times at the stations are fixed for each simulation setup resulting in station stop times ranging from $25 \mathrm{~s}$ to $150 \mathrm{~s}$. Each driving cycle is repeated five times with the DMU being stopped at the station until departure time in the station is reached. Within one simulation setup the duration of the whole journey including station stops is equal for conventional and hybrid DMU. Differences in travel time on track due to

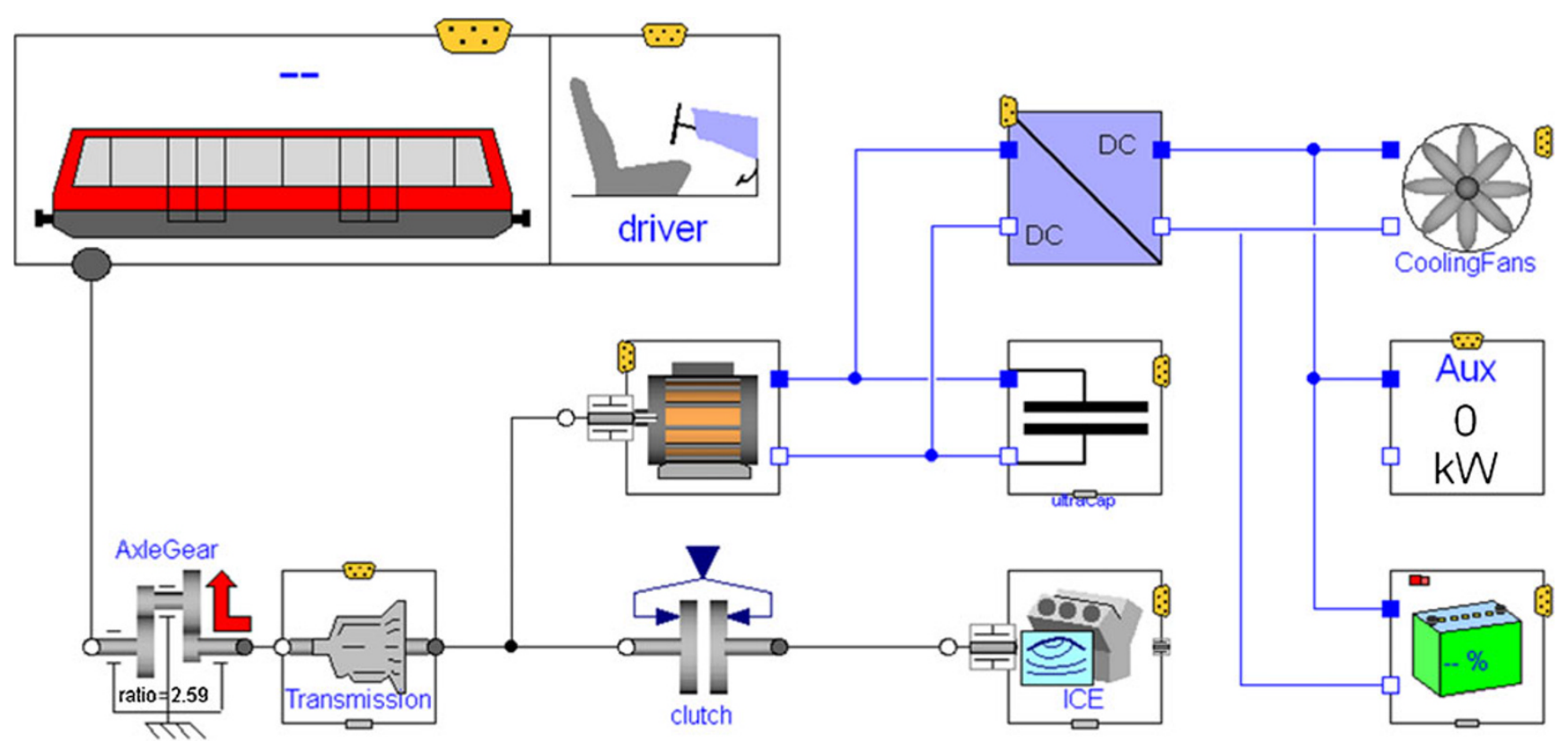

Fig. 8 Top layer of dymola simulation model 
Table 2 Vehicle and propulsion systems parameters of conventional and hybrid DMU conventional DMU

hybrid DMU

\begin{tabular}{|c|c|c|}
\hline \multicolumn{3}{|l|}{ Vehicle parameters } \\
\hline Davis coefficient $A$ & \multicolumn{2}{|l|}{$1850 \mathrm{~N}$} \\
\hline Davis coefficient B & \multicolumn{2}{|l|}{$70 \mathrm{~N} /(\mathrm{m} / \mathrm{s})$} \\
\hline Davis coefficient $\mathrm{C}$ & \multicolumn{2}{|l|}{$5 \mathrm{~N} /(\mathrm{m} / \mathrm{s})^{2}$} \\
\hline Total mass & $100 \mathrm{t}$ & $102 \mathrm{t}$ \\
\hline Max. acceleration/avg. deceleration & \multicolumn{2}{|l|}{$1.0 \mathrm{~m} / \mathrm{s}^{2} / 0.6 \mathrm{~m} / \mathrm{s}^{2}$} \\
\hline Max. velocity & \multicolumn{2}{|l|}{$140 \mathrm{~km} / \mathrm{h}$} \\
\hline \multicolumn{3}{|l|}{ Engine parameters } \\
\hline Rated power/rated torque & \multicolumn{2}{|c|}{$560 \mathrm{~kW}(2000 \mathrm{rpm}) / 3200 \mathrm{Nm}(1200 \mathrm{rpm})$} \\
\hline Fuel consumption (best point) & \multicolumn{2}{|l|}{$195 \mathrm{~g} / \mathrm{kWh}$} \\
\hline \multicolumn{3}{|l|}{ Transmission parameters } \\
\hline Gear ratio range/axle gear ratio & \multicolumn{2}{|l|}{$3.36-0.62 / 2.59$} \\
\hline \multicolumn{3}{|l|}{ Electric drive parameters } \\
\hline Generator power elec./max. torque & $60 \mathrm{~kW} / 770 \mathrm{Nm}$ & $200 \mathrm{~kW} / 2000 \mathrm{Nm}$ \\
\hline Motor power elec./max. torque & - & $90 \mathrm{~kW} / 1200 \mathrm{Nm}$ \\
\hline Fixed efficiency & $90 \%$ & $90 \%$ \\
\hline
\end{tabular}

higher acceleration rates are compensated by extended stop times in the stations. The station distances simulated are $5 \mathrm{~km}$ and $7.5 \mathrm{~km}$ with speed limits of 100, 120 and $140 \mathrm{~km} /$ h. Table 3 summarizes the drive cycle parameters and the calculated fuel savings compared to the conventional vehicle in the same drive cycle. The fuel savings are directly proportional to the reduction of $\mathrm{CO}_{2}$-emissions.

\subsection{Simulation results}

Mainly two factors contribute to fuel savings and $\mathrm{CO}_{2}$ reduction of the hybrid DMU. The first contributor is the additional power of the electric drive which leads to increased tractive effort. Therefore the hybrid DMU accelerates faster which results in longer coast phases where the diesel engine is switched off. This effect is apparent when comparing simulation setups 1, 2 and 3 or 6 , 7 and 8. The sooner the hybrid DMU starts coasting, the lower is the resulting fuel consumption compared to the conventional DMU.

The second contributor to fuel savings is the possibility to switch off the diesel engine during station stops. Inside stations the diesel engine is operated at low load because the power demanded by the auxiliaries is small. This operation regime results in low engine efficiency and therefore high specific fuel consumption. When comparing the simulation setups with identical maximum velocity and coasting position but different station stop times (i.e. setup 1 and 4 or 6 and 9) the velocity profile and therefore fuel consumption during driving is the same, but the fuel savings are higher when station stop time is increased.

The comparison of the different simulation setups with a station distance of $7.5 \mathrm{~km}$ indicates, that the fuel consumption reduction achieved with the hybrid system increases with decreasing velocity. In these driving cycles the average fuel consumption simulated with a maximum speed of $140 \mathrm{~km} / \mathrm{h}$ is $91.9 \%$ compared to $89.8 \%$ with a maximum speed of $120 \mathrm{~km} / \mathrm{h}$. Another important result is the correlation of fuel consumption reduction and station distance. Simulation setups 11, 12 and 13 refer to a station distance of $5 \mathrm{~km}$. All simulated cases with the shorter station distance show a significant reduction of fuel consumption compared to the setups with corresponding maximum speed and $7.5 \mathrm{~km}$ station distance.

In the following one exemplarily simulation setup is discussed in detail to illustrate the mechanisms leading to fuel savings. The results presented refer to simulation setup no. 10 which is a driving cycle with a station distance of
Fig. 9 Time dependent load profile of auxiliary systems

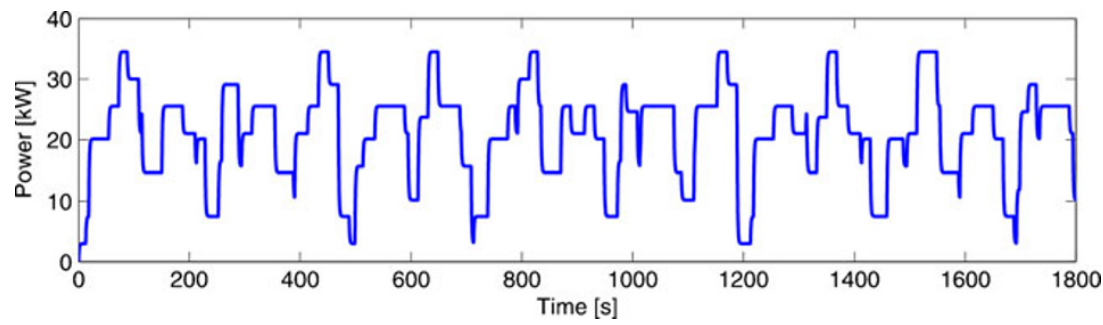


Table 3 Simulated drive cycles and fuel consumption compared to conventional DMU

\begin{tabular}{llllll}
\hline $\begin{array}{l}\text { Setup } \\
\#\end{array}$ & $\begin{array}{l}\text { Maximum } \\
\text { Velocity } \\
{[\mathrm{km} / \mathrm{h}]}\end{array}$ & $\begin{array}{l}\text { Station } \\
\text { Distance } \\
{[\mathrm{km}]}\end{array}$ & $\begin{array}{l}\text { Coasting } \\
\text { Position } \\
{[\mathrm{m}]}\end{array}$ & $\begin{array}{l}\text { Average } \\
\text { Station Stop } \\
\text { Time }[\mathrm{s}]\end{array}$ & $\begin{array}{l}\text { Fuel } \\
\text { consumption } \\
{[\%]}\end{array}$ \\
\hline 1 & 140 & 7.5 & 5500 & 93 & 93.0 \\
2 & 140 & 7.5 & 4450 & 87 & 91.1 \\
3 & 140 & 7.5 & 4000 & 83 & 90.3 \\
4 & 140 & 7.5 & 5500 & 43 & 93.6 \\
5 & 140 & 7.5 & 4450 & 37 & 91.6 \\
6 & 120 & 7.5 & 5500 & 73 & 90.3 \\
7 & 120 & 7.5 & 4950 & 69 & 89.7 \\
8 & 120 & 7.5 & 4000 & 51 & 88.5 \\
9 & 120 & 7.5 & 5500 & 23 & 90.7 \\
10 & 120 & 7.5 & 4950 & 19 & 90.0 \\
11 & 140 & 5.0 & 3000 & 97 & 89.7 \\
12 & 120 & 5.0 & 3000 & 88 & 86.6 \\
13 & 100 & 5.0 & 3000 & 65 & 89.4 \\
\hline
\end{tabular}

$7.5 \mathrm{~km}$, a time reserve of $3 \%$ and a maximum speed of $120 \mathrm{~km} / \mathrm{h}$. The simulated velocity profile and the power used for traction are displayed in Fig. 10. Due to the additional traction power the hybrid DMU accelerates faster than the conventional DMU. Eventually the hybrid DMU needs $15 \mathrm{~s}(18 \%)$ less time to reach maximum speed.

Power and state of charge (SOC) profiles of the storages (Fig. 11) illustrate this behaviour. When the DMU is stopped the battery powers the auxiliary units. After $30 \mathrm{~s}$ the peak in double layer capacitor power marks the moment when the diesel engine is started. During acceleration in first gear the diesel engine powers the DMU without traction support from the storage because the engine torque already exceeds the torque limit of the hydrodynamic
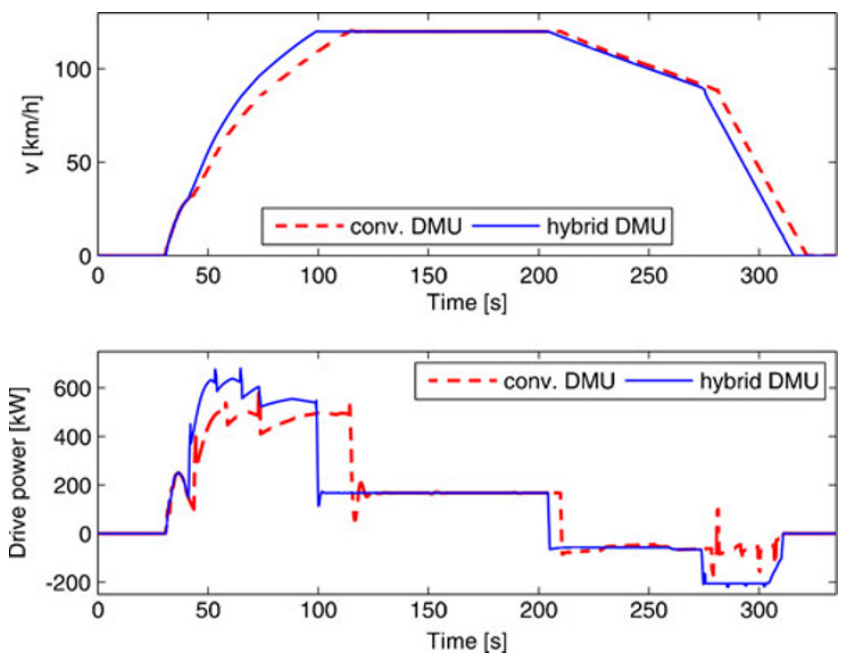

Fig. 10 Velocity profile (top) and drive power (bottom) of conventional and hybrid DMU
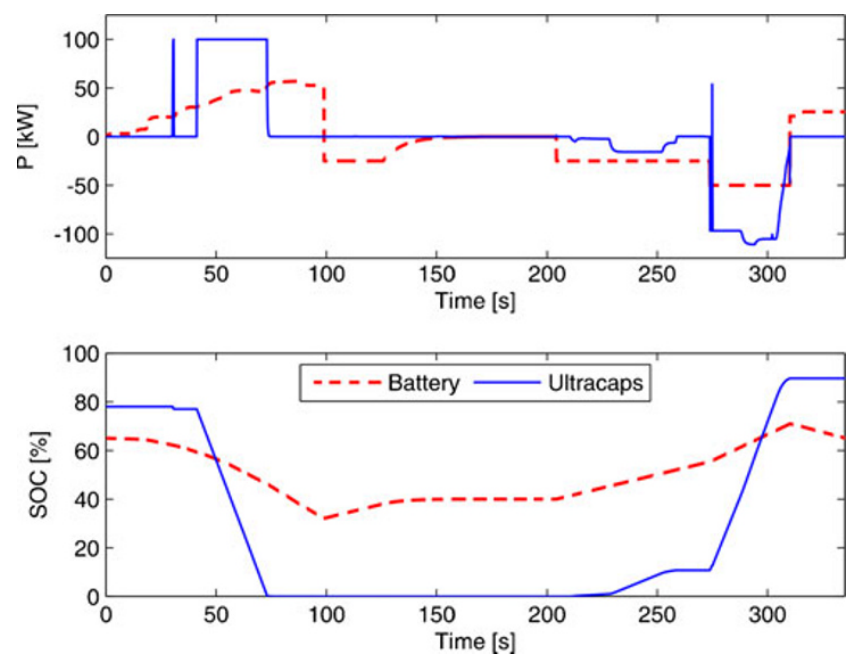

Fig. 11 Power at storage terminals (top) and state of charge (bottom) of battery and double layer capacitor storage

torque converter. After $45 \mathrm{~s}$ the transmission shifts to second gear and the electric drive supports traction. Auxiliaries and engine cooling are powered by the battery. The engine power used to drive these components in conventional DMU is available as additional tractive power in hybrid DMU. When the double layer capacitor is discharged the battery still powers the auxiliaries. Therefore even with empty double layer capacitor more engine power is available for traction than in the conventional DMU.

Fig. 12 displays the primary energy consumption of conventional and hybrid DMU and the distribution of energy. The fuel consumption of the hybrid DMU is reduced by $10 \%$ compared to the conventional DMU, $\mathrm{CO}_{2}$-emissions are reduced by the same percentage. As a result of avoiding operating the diesel engine at low load during station stops engine efficiency is increased from $37.3 \%$ in the conventional DMU to $40 \%$ in the hybrid vehicle. The amount of energy dissipated in the mechanical brakes is reduced by $38 \%$ and the energy needed to overcome running resistance is slightly increased to $1.9 \%$ as a result of the increased velocity during acceleration phase. The losses in the drive train components including energy storages are significantly higher than in the conventional DMU. This is caused by the recuperation because additional losses emerge from the transmission, electric drive and storage components.

\section{Test bench setup}

In addition to modelling and simulation of the entire rail vehicle, a hardware test bench is developed to validate the thermal and electrical behaviour of the HES concept. Furthermore, an alternative way of realizing a hardware in the loop test bench with the tool chain Modelica, 
Fig. 12 Simulated energy consumption of conventional and hybrid DMU (top) and distribution of primary energy (bottom) amongst diesel engine (ICE), running resistance (Res), brake (MechBrake), drive train losses (DriveTrain), and auxiliaries \& engine cooling (Aux \& Cooling)
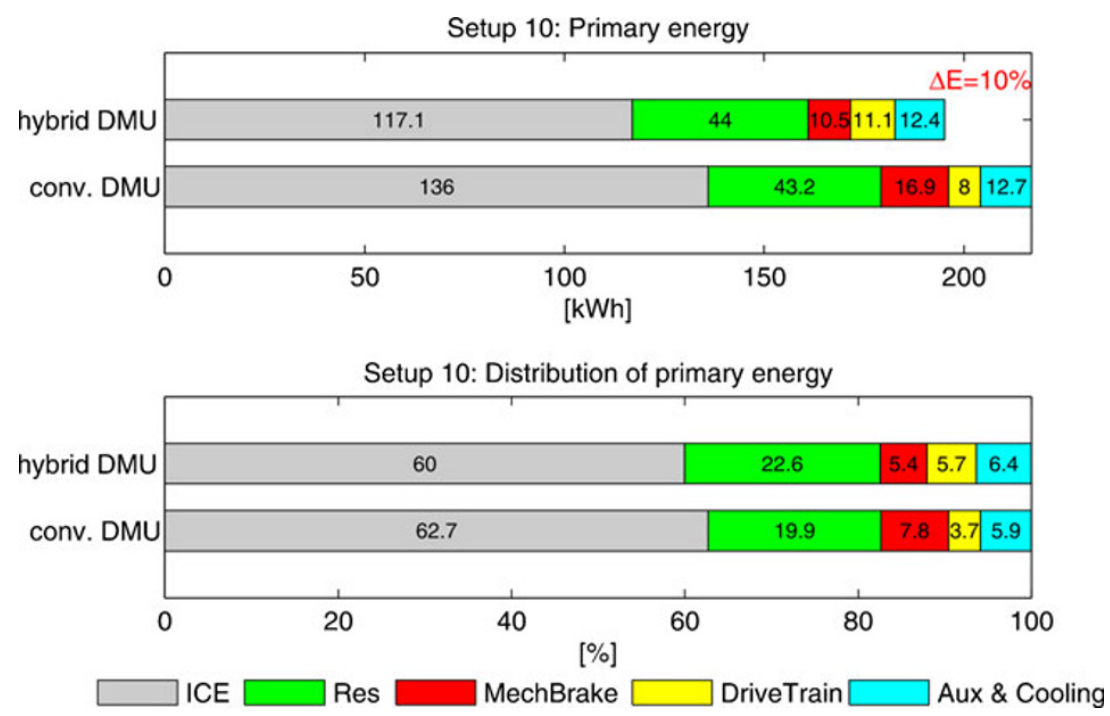

MATLAB/Simulink and XPC is shown. To reduce technical effort and costs, a scaled hardware model of the hybrid energy storage is set up and tested by electronically controlled sources and loads. Due to electrical safety reasons the maximum operating voltage of the entire test bench is limited to $50 \mathrm{~V}$. A combination of purchasable hardware components is selected which results in a scaling factor regarding energy storage capacity and continuous power capability compared to the real sized energy storage (Table 4).

A step-down converter with a maximum output current of 250 A connects the different voltage levels of battery and double layer capacitor. The power limit of the step-down converter at battery voltage level is approximately $3 \mathrm{~kW}$ corresponding to $96 \mathrm{~kW}$ at $410 \mathrm{~V}$ for the real sized system. Taking into account the scaling factors between real system and test bench components, the K2 Energy battery [23] and the Maxwell double layer capacitor stack [24] on the test bench each behave like one pack in the real sized system. The main difference between real system and test bench system is the voltage ratio between double layer capacitor and battery. In the real sized system battery voltage is $1 / 2$, whereas on the test bench the voltage is $1 / 4$ of maximum double layer capacitor voltage. Nevertheless the increased losses of the DC/DC converter due to its lower efficiency are expected to be small.

Except of electric drive, energy storages, DC/DCconverter and auxiliary load all drive train components are simulated by the Modelica hybrid DMU model introduced before. The signals needed to control the system are fed to the simulation model from measured values of the corresponding test bench components.

In general, system models must be strongly simplified to make them run on a hard real time system like dSPACE or xPC. Especially the usage of highly efficient variable step solvers like DASSL is not possible in hard real time mode. To avoid any loss of modelling precision a client/server architecture is chosen. The system simulation runs on a conventional PC and acts as a simulation server for a lean hard real time task which implements the control and safety system. The latter is implemented in MATLAB/Simulink and runs on an $\mathrm{xPC}$ real time system. The communication and synchronization of both systems is realized via a dedicated point-to-point Ethernet connection using the User Data Protocol (UDP).

Starting from the real time system (xPC) all other components and measuring systems are controlled via a Controller Area Network (CAN). The electrical motor/
Table 4 Comparison of real sized system and test bench model

\begin{tabular}{lllccc}
\hline & Parameter & Unit & Real system & Test system & Scaling factor \\
\hline Double layer capacitor & $\mathrm{C}_{\text {Cap }}$ & $\mathrm{F}$ & 20.6 & 165.0 & 0.125 \\
& $\mathrm{U}_{\text {Max }} / \mathrm{U}_{\text {Min }}$ & $\mathrm{V}$ & $777.6 / 440.0$ & $48.6 / 27.5$ & 16 \\
& $\mathrm{P}_{\mathrm{Cont}}$ & $\mathrm{kW}$ & 182.6 & 5.7 & 32 \\
& $\mathrm{E}_{\mathrm{Min}} / \mathrm{E}_{\mathrm{Max}}$ & $\mathrm{Wh}$ & $554.6 / 1732.1$ & $17.3 / 54.1$ & 32 \\
& $\mathrm{Q}_{\text {Batt }}$ & $\mathrm{Ah}$ & 72.0 & 72.0 & 1 \\
& $\mathrm{U}_{\text {Nom }}$ & $\mathrm{V}$ & 409.6 & 12.8 & 32 \\
& $\mathrm{P}_{\mathrm{Nom}}$ & $\mathrm{kW}$ & 57.3 & 1.8 & 32 \\
& $\mathrm{E}_{\text {Nom }}$ & $\mathrm{kWh}$ & 29.5 & 0.92 & 32 \\
\hline
\end{tabular}


Fig. 13 Hybrid energy storage test bench setup for HiL Simulation

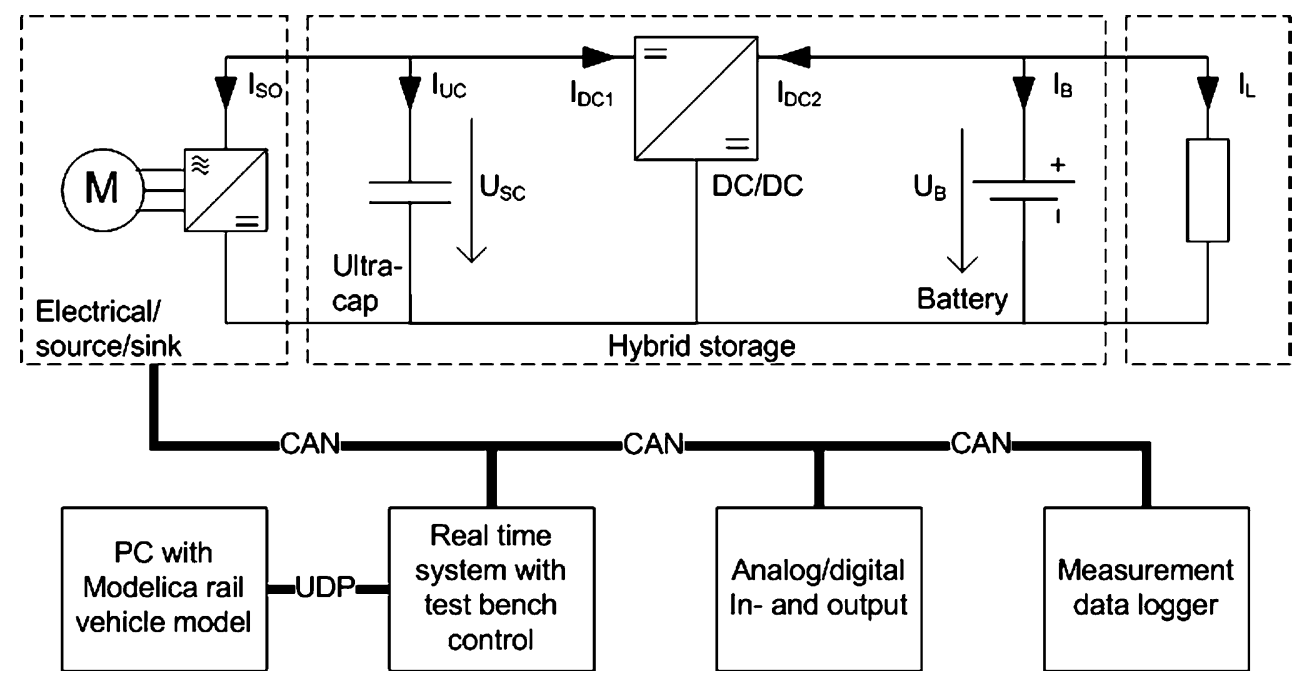

generator is emulated by a Digatron EVT 600-650 IGBT battery test device. This battery test device provides continues power up to $150 \mathrm{~kW}$, voltages up to $650 \mathrm{~V}$ and a maximum current of $600 \mathrm{~A}$. In the test setup it works as an electrical source/sink (Fig. 13). Any auxiliaries as well as the engine cooling are emulated by an electrical load, using an analogue signal/CAN converter module for communication. The power flow between double layer capacitor and battery is regulated by the DC/DC converter also using an analogue signal/CAN converter.

In addition to the test bench control, all major measurands are collected by analogue signal/CAN converters and a CAN data logger manufactured by IMC. The voltage measurement of double layer capacitor and battery is done by the analogue signal/CAN converter directly. For current measurements a current transducer is used which allows a galvanic isolated and lossless measurement. For validating the thermal behaviour, resistance thermometers (PT100) are placed at the hotspot of each component. Main focus is the temperature of double layer capacitor and LiFePO battery.

\section{Test bench results}

In the following measured results for setup no. 10 (vMax $120 \mathrm{~km} / \mathrm{h}$, station distance $7.5 \mathrm{~km}$, time reserve $3 \%$, station stop time $20 \mathrm{~s}, 5$ driving cycles) are compared to simulation results. Measured and simulated results are in quite good accordance with each other although slight differences are found in the voltage and current profiles of the energy storages. Fig. 14 displays both results with measured values being scaled up to the real system size using the scaling factors defined in Table 4. Measured battery and double layer capacitor currents show ripples originating from the internal control of the $\mathrm{DC} / \mathrm{DC}$ converter, but anyway the simulated currents are close to the measured ones. The maximum deviation of simulated and measured battery currents is found at $t=110 \mathrm{~s}$ with an absolute difference of 45A. Simulated voltages are also in good accordance to measured voltages, but due to the difference in battery current the measured voltage differs by $3.4 \%$ from the simulated battery voltage. The maximum relative error of the double layer capacitor voltage is $9.8 \%$ at $t=272 \mathrm{~s}$.
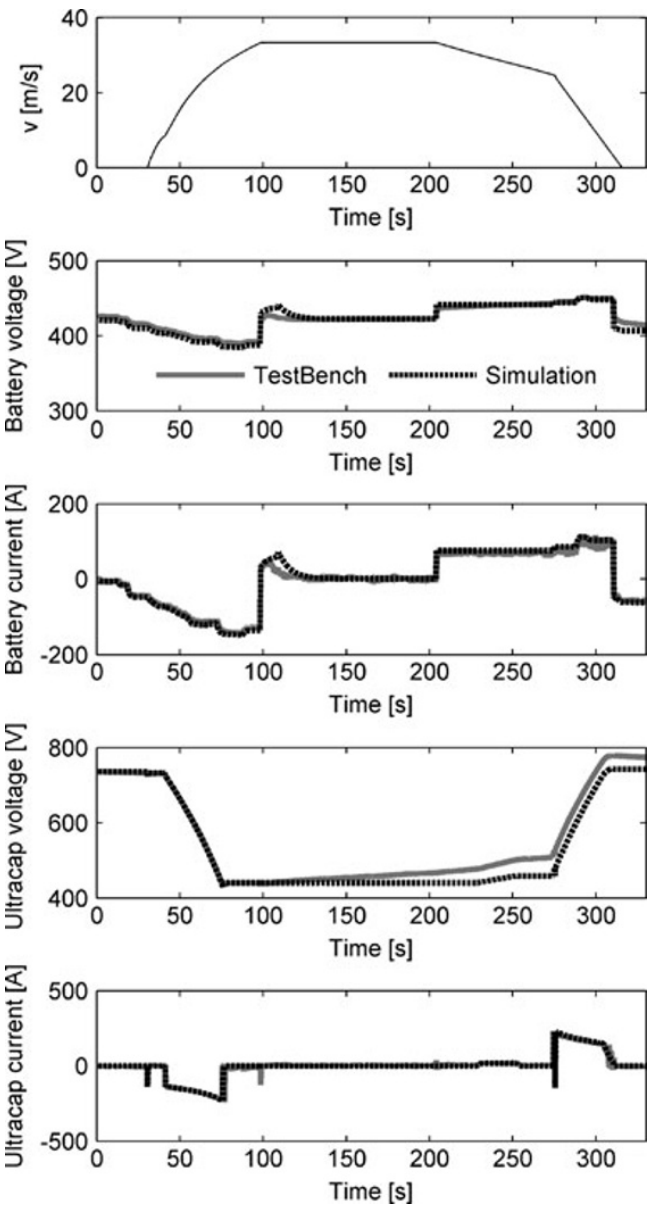

Fig. 14 Comparison of simulated and measured battery and double layer capacitor voltage/current 
During the measurement the battery temperature increased by roughly $2^{\circ} \mathrm{C}$ and the double layer capacitor temperature rose roughly $1^{\circ} \mathrm{C}$.

The measurements show additional effects which are not modelled in the storage models used in the simulation model. For example the simulated double layer capacitor voltage remains constant when the lower voltage limit of $440 \mathrm{~V}$ is reached. In contrast the measurements show a rising voltage level although only a minimal current is fed to the double layer capacitor. The differences in simulated and measured voltages are due to an offset in the DC/DC converter control.

Although an active cooling of the storages was not necessary on the test bench the results of the measured driving cycle setup do not allow the evaluation of long term thermal behaviour. To clarify which kind of cooling (air cooling, forced air cooling or fluid cooling) is required for a real size hybrid energy storage additional long time measurements under defined boundary conditions have to be performed.

\section{Conclusions}

The presented paper describes a new concept for a hybrid hydro-mechanical DMU. This new concept allows fuel savings ranging from 6 up to more than $13 \%$ depending on operational parameters such as maximum speed and station distance. Corresponding to the fuel savings $\mathrm{CO}_{2}$-emissions are also reduced by 6 to $13 \%$. In addition the new concept also enables switching off the diesel engine while the DMU is stopped in stations leading to reduced noise and pollutant emissions in the station area.

For the new concept a hybrid energy storage system consisting of battery and double layer capacitors was developed. Compared to battery or double layer capacitor storage systems the hybrid storage is better suited for the requirements and saves roughly $20 \%$ of weight.

A scaled model of the hybrid storage was built on a hardware-in-the-loop test bench where a simulation model of the train propulsion system controlled power flows in the hybrid storage system. The measurements of battery and double layer capacitor voltages and currents have shown good accordance to the simulated values. As a major result a tool chain was developed which allows to use the same Dymola software model for the theoretical simulations and to control hardware devices on the HiL test bench.

On the test bench temperatures of battery and double layer capacitor storage could be measured. The HiL-test bench enables validation of models but additional measurements have to be performed to evaluate thermal behaviour of the storages and to develop an appropriate cooling concept for the hybrid storage.
In the future also the simulation models of the storages have to be improved concerning modelling of thermal behaviour. Also a reliable method to detect the actual state of charge of the storage while they are in operation has to be developed.

Open Access This article is distributed under the terms of the Creative Commons Attribution License which permits any use, distribution and reproduction in any medium, provided the original author(s) and source are credited.

\section{References}

1. "Unsere Schienenfahrzeuge im Regional- und Stadtverkehr", Publication by Deutsche Bahn AG, 12/2003, available at http://www. deutschebahn.com/site/shared/en/file attachements/publications broschures/regional_urban_rolling__stock.pdf, Date: 20th of December 2010

2. Allianz pro Schiene (2006) Bestandszahlen der Diesel- und Elektrotriebfahrzeuge (Anteil der Dieseltraktion am Gesamtbestand 2004)

3. Tretow H-J, Weclas M (2002) Fahrzeugantriebe-Stand der Technik und Perspektiven, Sonderdruck Schriftenreihe der Georg-Simon-Ohm-Fachhochschule Nürnberg Nr. 17, ISSN 1616-0762, Nürnberg, Germany

4. Nolte R (2003) EVENT-Evaluation of energy efficiency technologies for rolling stock and train operation of railways, Final Report, Commissioned by Union Internationale des Chemins de fer (UIC), Paris, France

5. Oettich S (2005) Die flexible S-Bahn: Energiesparende und anschlussoptimierende Flexibilisierung der Fahrweisen und Fahrzeiten, PhD Thesis, Technische Universität Dresden

6. Meyer M, Lerjen M et al (2008) Das Energiesparprogramm der SSB, SER - Schweizer Eisenbahn Revue(07/2008)

7. Peckham C (2007) T618-Improving the efficiency of Traction Energy Use, Final Report, Rail Safety and Standards Board, London, UK

8. Bartosch S (2009) Umweltfreundlich auf der Schiene-Voith Power Pack mit Eco-Komponenten, 4. ÖPNV-Innovationskongress BaWü, March 9th-11th 2009, Freiburg, Germany

9. Knörr W, Borken J (2003) Erarbeitung von Basisemissionsdaten des dieselbetriebenen Schienenverkehrs unter Einbeziehung möglicher Schadstoffminderungstechnologien, Final Report, Förderkennzeichen 29943 111. Umweltbundesamt, Germany

10. Nick M (2002) Hybridantrieb mit Nutzung der Bremsenergie bei Dieseltriebwagen, EI-Eisenbahningenieur 53(09/2002)

11. Dittus H (2009) Reducing Diesel Railcar CO2-Emissions by means of Electric Energy Storages, ECTRI Young Researchers Seminar 2009, June 3rd-5th 2009, Torino, Italy

12. Pehnt M (2001) Ökologische Nachhaltigkeitspotenziale von Verkehrsmitteln und Kraftstoffen, STB-Bericht Nr. 24, Deutsches Zentrum für Luft und Raumfahrt-Institut für Technische Thermodynamik, Stuttgart, Germany

13. Behmann U (2009) Rückspeisen von Bremsenergie bei der DB, eb -Elektrische Bahnen 2009(1-2)

14. Hillmansen S, Roberts C et al (2009) DMU Hybrid Concept Evaluation-Follow on Work DfTRG/0078/2007 funded by Department for Transport. University of Birmingham, UK

15. Furuta R, Kawasaki J et al (2010) Hybrid traction technologies with energy storage devices for nonelectrified railway lines. IEEJ Trans 2010(5):291-297 
16. Ogasa M (2010) Application of energy storage technologies for electric railway vehicles - examples with hybrid electric railway vehicles. IEEJ Trans 2010(5):304-311

17. Kondo K (2010) Recent energy saving technologies on railway traction systems. IEEJ Trans 2010(5):298-303

18. Söffker C, Tutzauer R (2007) Bahn-Antriebstechnik für sensible Streckenabschnitte und zur Energierückgewinnung, eb-Elektrische Bahnen 2007(7)

19. Steiner M, Klohr M et al (2007) Energy storage system with ultracaps on board of railway vehicles, EPE 2007-12th European Conference on Power Electronics and Applications, September 2nd-5th 2007, Aalborg, Denmark

20. Lunz B, Sinhuber P et al (2009) Potenziale von Energiespeichern zur Elektrifizierung des Nahverkehrs. Der Nahverkehr 2009(7-8)

21. Sauer D (2007) Speichertechnologien für Hybrid- und Elektrofahrzeug, Internationaler ETG-Kongress 2007, October 23rd-24th 2007, Karlsruhe, Germany
22. Uhlenhut A (2009) Oberleitungsfreier Straßenbahnbetrieb mit Sitras MES und Sitras HES. Verkehr und Technik 2009 (6)

23. "LFP300HPS", Manufacturer Datasheet, K2 Energy, Henderson, Nevada, USA, Datasheet available on request at http://www. peakbattery.com/index.html

24. "BMOD0165 P048", Manufacturer Datasheet, Maxwell Technologies, San Diego, USA http://www.maxwell.com/docs/DATA SHEET_48V_SERIES_1009365.PDF, Date: 20th of December 2010

25. Riegel B (2009) Energiespeicher: Schlüsseltechnologie für die Elektromobilität, Der Nahverkehr (7-8)

26. Fritzson P (2004)) Principles of Object-oriented Modeling and Simulation with Modelica 2.1. Wiley-IEEE, Piscataway

27. Hülsebusch D, Ungethüm J et al (2009) Multidiszilinäre Simulation von Fahrzeugen. ATZ-Automobiltechnische Zeitschrift 2009 (10) 